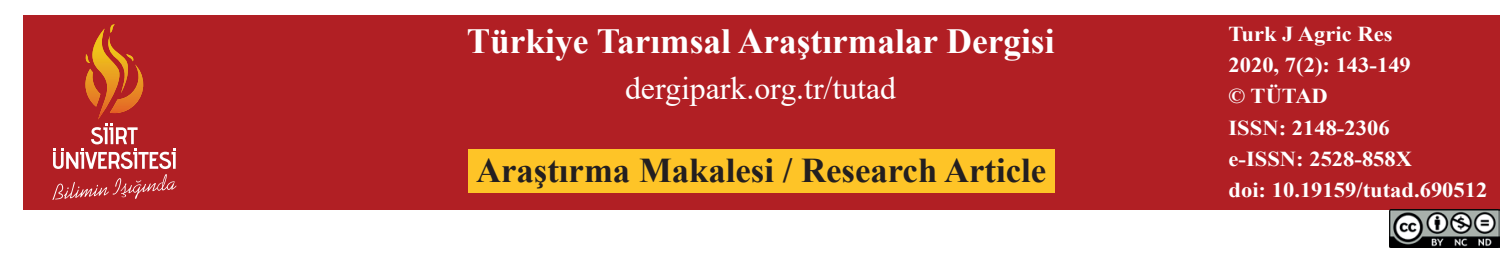

\title{
Farklı Bitki Uçucu Yağlarının Acanthoscelides obtectus (Say) (Coleoptera: Chrysomelidae: Bruchinae) Erginleri Üzerindeki Etkileri
}

\author{
Alime BAYINDIR EROL ${ }^{1 *}$, Ali Kemal BİRGÜC $\ddot{U}^{2}$ \\ ${ }^{\prime}$ Pamukkale Üniversitesi, Uygulamalı Bilimler Yüksekokulu, Organik Tarm İşletmeciliği Bölümü, Çivril-Denizli, TÜRKiYE \\ ${ }^{2}$ Isparta Uygulamalı Bilimler Üniversitesi, Ziraat Fakültesi, Bitki Koruma Bölümü, Isparta, TÜRKIYE
}

\begin{tabular}{ll}
\hline \multicolumn{1}{c}{ Geliş Tarihi/Received: 17.02 .2020} & Kabul Tarihi/Accepted: 22.06 .2020 \\
\hline ORCID ID (Yazar sırasına göre / by author order) & \\
(Dorcid.org/0000-0001-6845-5915 Dorcid.org/0000-0001-9497-4700 \\
"Sorumlu Yazar/Corresponding Author: abayindir@pau.edu.tr
\end{tabular}

Öz: Acanthoscelides obtectus (Say) (Coleoptera: Chrysomelidae: Bruchinae) tohum kabuğunda delikler açarak kotiledonlar ile beslenmesi sonucunda, diğer böceklerin ve mikroorganizmaların girişini kolaylaştıran fasulyenin önemli zararlılarından biridir. Bu çalışmada; ardıç (Juniperus communis), çay ağacı (Melaleuca alternifolia), kekik (Thymus vulgaris), lavanta (Lavandula hybrida), okaliptus (Eucalyptus globulus) ve sarımsak (Allium sativum) gibi bitki uçucu yağlarının A. obtectus erginleri üzerinde uzaklaştırıcı ve fumigant etkileri araştırılmıştır. Uzaklaştıııı etkinin belirlenmesi amacıyla şeffaf bir plastik tüpün bir ucuna uçucu yağ, diğer ucuna ise saf su emdirilmiş filtre kâğttları konulmuş ve 24 saat sonunda ergin bireylerin yönelimleri izlenmiş̧tir. Fumigant etkinin belirlenmesi amacıyla ise uçucu yağ emdirilmiş filtre kağıtları cam kavanozların kapaklarına sabitlenmiş ve kavanoz içerisindeki canlı birey sayıları 1., 3., 5., ve 7. günlerde kaydedilmiş̧ir. Çalışmanın ilk aşamasında uçucu yağların zararlıya karşı uzaklaştırıcı etki indeksleri (RI) sırasıyla $-9.68,20.00,-25.00,-11.76,17.39$ ve 18.18 șeklinde hesaplanmıștır. Bu uçucu yağların zararlıya karșı uzaklaştırıcı etki indeksleri istatistiksel olarak önemsiz bulunmuştur. Çalışmanın ikinci aşamasında her bir uçucu yağın 1000, 3000 ve $5000 \mathrm{ppm} \mathrm{L}^{-1}$ 'lik dozlarının A. obtectus erginleri üzerinde fumigant etkileri belirlenmiștir. Kullanılan uçucu yağların tüm dozlarının uygulanması sonucunda, uçucu yağlar arasında istatistiksel olarak bir fark kaydedilmemiş̧tir. En yüksek ölüm oranları, ardıç uçucu yağının $5000 \mathrm{ppm} \mathrm{L}^{-1}$ 'lik doz uygulamasında 1., 3., 5. ve 7. gün sayımlarında $\% 25.33, \% 30.67, \% 44.00$ ve $\% 62.67$ ölüm oranlarının kaydedilmesiyle elde edilmiştir. Sonuç olarak, bu uçucu yağlar arasında hem uzaklaştırıcı etki hem de fumigant etkileri bakımından istatistiksel bir fark bulunmamasına rağmen, zararlı ile mücadele de insan ve çevre üzerinde olumsuz etkilerinin olmaması bakımından tercih edilebilir.

Anahtar Kelimeler: Ardıç uçucu yağı, fasulye tohum böceği, fumigant etki, uçucu yağlar, uzaklaştırıcı etki

\section{Effects of Different Plant Essential Oils on Acanthoscelides obtectus (Say) (Coleoptera: Chrysomelidae: Bruchidae) Adults}

\begin{abstract}
Acanthoscelides obtectus (Say) (Coleoptera: Chrysomelidae: Bruchinae) is one of the important pests of the bean that facilitates the entry of other insects and microorganisms as a result of opening holes in the seed coat to feed with cotyledons. In this study, repellent and fumigant effects of different essential oils, such as juniper (Juniperus communis), tea tree (Melaleuca alternifolia), thyme (Thymus vulgaris), lavender (Lavandula hybrida), eucalyptus (Eucalyptus globulus) and garlic (Allium sativum), on A. obtectus adults were investigated. To determine the repelling effect, filter papers absorbed with essential oil and pure water were placed on each end of a transparent plastic tube and after 24 hours the orientation of adult individuals was followed. In order to determine the fumigant effect, filter papers impregnated with essential oil were fixed on the lids of the glass jars, and the numbers of living individuals in the jar were recorded on the $1^{\text {st }}, 3^{\text {rd }}, 5^{\text {th }}$ and $7^{\text {th }}$ days. In the first stage of the study, the repellent index (RI) of these essential oils was calculated as $-9.68,20.00,-25.00,-11.76,17.39$, and 18.18 , respectively. The repellent index of these essential oils was statistically insignificant. In the second stage of the study, fumigant effects on $A$. obtectus adults were determined by using 1000,3000 , and $5000 \mathrm{ppm} \mathrm{L}^{-1}$ doses of each essential
\end{abstract}


oil. As a result of the application of all doses of the essential oils used, no statistically significant difference was observed between the essential oils. The highest mortality rates were obtained by recording the $25.33 \%, 30.67 \%, 44.00 \%$, and $62.67 \%$ mortality rates on the $1^{\text {st }}, 3^{\text {rd }}, 5^{\text {th }}$, and $7^{\text {th }}$ days of the $5000 \mathrm{ppm} \mathrm{L}^{-1}$ dose of juniper essential oil, respectively. As a result, although there is no statistical difference between these essential oils in that both repellent effect and fumigant effects, pest control can be preferred in the way of not having negative effects on human and the environment.

Keywords: Juniper essential oil, bean seed beetle, fumigant effect, essential oils, repellent effect

\section{Giriş}

Depo ürünlerinde zarar oluşturan böcekler arasında Bruchinae alt familyasindan Acanthoscelides obtectus (Say) (Coleoptera) türü yer almaktadır (Papachristos ve Stamopoulos, 2002). Primer zararlı konumunda olan fasulye tohum böceğinin konukçuları, Fabaceae familyasından Phaseolus vulgaris L. ve Vigna L. cinsine ait bitki türleridir (Dobie ve ark., 1984). A. obtectus fasulyenin önemli zararlılarından biri olup, tohum kabuğunda delikler açarak kotiledonlar ile beslenmesi sonucunda diğer böceklerin ve mikroorganizmaların girişini kolaylaştırmaktadır (Jimenez ve ark., 2017). Böylece tohumların besin değerleri ve kalitesi yanında, çimlenme özelliklerini de düşürmektedir (Gallo ve ark., 2002). Bununla birlikte uygun depolanma koşullarının sağlandığı ülkelerde tohumlarda kayılar \% 20-40 civarında olurken (Pemonge ve ark., 1997), Türkiye'de uygun depolama koşulları sağlanamadığından dolayı bu kayıplar \% 100'lere ulaşabilmektedir (Yıldırım ve ark., 2001).

Depolanmış tohumlarda zararlıların kontrolünde genel olarak sentetik insektisitler ve fumigantlar kullanılmaktadır (Mueller, 1990; Jembere ve ark., 1995; Okonkwo ve Okoye, 1996; Huang ve Subramanyam, 2005). Ancak bu kimyasalların yoğun olarak kullanımı sonucunda zararlı popülasyonlarda direnç, gıda maddelerinde kalıntı, insan ve çevre üzerinde olumsuz etkiler meydana gelmektedir (Lee ve Lees, 2001; Isman, 2006; Roel ve Vendramim, 2006). Bu etkilerden dolayı alternatif mücadele yöntemlerinden olan uçucu yağlar üzerine olan çalışmalara yoğunluk verilmiştir (Bakkali ve ark., 2008; Chu ve ark., 2010; Ebadollahi, 2011). Uçucu yağlar başlıca Myrtaceae, Lauraceae, Lamiaceae ve Asteraceae familyalarına ait 17500 aromatik bitki türünden elde edilmektedir (Regnault-Roger ve ark., 2012). Uçucu yağların böceklerin; davranışı, beslenme, büyüme, gelişme ve üreme üzerine etkilerinin olduğu bildirilmektedir (Coast, 1994; Nerio ve ark., 2009; Tripathi ve ark., 2009; Birgücü ve ark., 2014). $\mathrm{Bu}$ çalışmada; ardıç (Juniperus communis), çay ağacı (Melaleuca alternifolia), kekik (Thymus vulgaris), lavanta (Lavandula hybrida), okaliptus (Eucalyptus globulus) ve sarımsak (Allium sativum) uçucu yağlarının, depo zararlılarından olan $A$. obtectus erginleri üzerinde uzaklaştırıcı ve fumigant etkilerinin bulunup bulunmadığı araştırılmıştır.

\section{Materyal ve Yöntem}

Çalışmanın ana materyalini A. obtectus ergin bireyleri ve Tablo 1'de verilen uçucu yağlar oluşturmaktadır. Hem A. obtectus ergin bireylerinin üretimi hem de uçucu yağların uzaklaştırıcı ve fumigant etki denemeleri $25 \pm 1{ }^{\circ} \mathrm{C}$ sicaklık, \% 60 $\% 5$ orantılı nem ve karanlık ortam koşullarının sağlandığı iklimlendirme dolaplarında yürütülmüştür.

\subsection{Böcek üretimi}

Acanthoscelides obtectus erginleri ile bulaş1k fasulye $(P$. vulgaris L.) tohumları laboratuvar koşullarında kültüre alınmıştır. Ergin bireylerin üretilmesinde $20 \times 14 \times 10 \mathrm{~cm}$ boyutlarında plastik kültür kapları kullanılmıştır. Bu kaplarının üzeri $10 \times 10 \mathrm{~cm}$ ebatlarında kesilerek üzeri tül ile kapatılmıştır. Aynı yaş grubunda ergin bireyler elde edebilmek için bu plastik kaplara, 250 gram temiz fasulye tohumları konarak, ergin bireylerin 3-4 gün süre ile yumurta bırakmaları sağlanmıştır. $\mathrm{Bu}$ sürenin sonunda ergin bireyler ortamdan uzaklaştırılarak, yumurtalardan ergin çıkışı beklenmiştir.

Tablo 1. Araştırmada kullanılan uçucu yağların elde edildiği bitkilerin bilimsel isimleri ve elde edildiği bitki kisimlar1 ${ }^{*}$

\begin{tabular}{llll}
\hline İsim & Bilimsel isim & Familya & Elde edilen kisım \\
\hline Ardıc & Juniperus communis L. & Cupressaceae & Tohum \\
Çay ağacı & Melaleuca alternifolia (Maiden \& Betche) Cheel & Myrtaceae & Yaprak ve dal uçları \\
Lavanta & Lavandula hybrida & Lamiaceae & Yaprak ve çiçek/tomurcuk \\
Kekik & Thymus vulgaris L. & Lamiaceae & Yaprak ve dalları \\
Okaliptus & Eucalyptus globulus Labill & Myrtaceae & Yaprak \\
Sarımsak & Allium sativum L. & Liliaceae & Tohum \\
\hline
\end{tabular}

*: Denemelerde Biorganix life ${ }^{\circledR}$ ticari uçucu yağları kullanılmıştır. 


\subsection{Denemelerin kurulması}

\subsubsection{Uzaklaştırıcı etki denemelerinin kurulması}

Acanthoscelides obtectus erginleri üzerinde Tablo 1'de verilen uçucu yağların uzaklaştırıcı etkilerinin araştırılmasında her bir uçucu yağın 25000 ppm L ${ }^{-1}$ 'lik dozu kullanılmıştır. Belirtilen dozlarda hazırlanan uçucu yağlar pipet yardımıyla alınarak 1x1 cm ebatlarında kesilen filtre kağıtlarına pipet yardımıyla emdirilmiștir. Uzaklaştırıcı etki denemelerinde hazırlanan $7 \mathrm{~cm}$ çapında ve $30 \mathrm{~cm}$ uzunluğunda şeffaf plastik tüpler kullanılmıştır. Bu tüplerin bir ucuna uçucu yağ, diğer ucuna ise kontrol grubu oluşturması için sadece saf su emdirilmiş belirtilen ebatlarda filtre kağıtları konulmuştur. Bu şeffaf plastik tüplerin tam orta kısmında $3 \mathrm{~cm}$ çapında bir delik açılarak ve bu açıklığa $20 \mathrm{~cm}$ uzunluğunda bir başka plastik şeffaf tüp yerleştirilmiştir. Oluşturulan bu düzenek içerisine 20 adet $A$. obtectus ergini salınmıştır. Denemelerde 24 saat sonunda ergin bireylerin düzeneğin hangi kısmında bulunduğu belirlenerek kaydedilmiştir.

\subsubsection{Fumigant etki denemelerinin kurulması}

Acanthoscelides obtectus erginlerine Tablo 1'de verilen uçucu yağların fumigant etkilerinin araștırılmasında her bir uçucu yağın 1000, 3000 ve 5000 ppm L ${ }^{-1}$ 'lik dozu kullanılmıştır. Uçucu yağlar $1 \mathrm{x} 1 \mathrm{~cm}$ ebatlarında kesilen filtre kâğıtlarına pipet yardımıyla emdirilmiş ve denemenin kurulacağ 1 cam kavanozların kapaklarına sabitlenmiştir. Denemelerde kültür kaplarından emgi şişesi yardımıyla $15^{\prime}$ 'er adet aynı yaş grubundan ergin bireyler çekilerek, denemelerin yapılacağ 1 litrelik cam kavanozlara aktarılmıștır. Ayrıca erginlerin beslenmesi için, her bir deneme kavanozuna 10 adet temiz fasulye tohumu bırakılmıştır. Böylece hazırlanan her bir kavanoz bir tekerrür olmak üzere, denemeler beş tekerrürlü olarak yürütülmüştür. Uygulamaların 1., 3., 5., ve 7. günlerinde sayımlar yapılarak canlı bireyler kaydedilmiştir.

\section{3. İstatistiksel değerlendirme}

Acanthoscelides obtectus erginlerine uçucu yağların uygulanması sonucunda elde edilen verilere iki yönlü $\mathrm{t}$ testi (Paired-samples $\mathrm{t}$ test) uygulanmıştır $(p \leq 0.05)$. Ayrıca, ergin birey sayıları üzerinden her bir uçucu yağın uzaklaştırıcı indeksleri Eşitlik 1 (Pascual-Villalobos ve Robledo, 1998; Birgücü ve ark., 2016) yardımıyla hesaplanmıştır.

$$
\mathrm{RI}=[\mathrm{C}-\mathrm{T}) /(\mathrm{C}+\mathrm{T})] \times 100 .
$$

Eşitlikte RI, uzaklaştırıcı indeksini; C, kontrol uygulanmış ergin birey sayısını; T, ise uçucu yağ uygulanmış ergin birey sayısını ifade etmektedir.
Fumigant etki testlerinde 1., 3., 5. ve 7. gün sayım sonuçlarında canlı bireyler üzerinden veriler değerlendirilmiştir. Abbott (1925) tarafından bildirilen Eşitlik 2 kullanılarak düzeltilmiş yüzde (\%) ölümler hesaplanmıştır.

$$
[(A-B) / A] \times 100
$$

Eşitlikte $A$, kontroldeki \% canlıyı; $B$, muameledeki \% canlıyı ifade etmektedir.

$\mathrm{Bu}$ denemelerden elde edilen verilere, tek yönlü varyans analizi (One-Way ANOVA) uygulandıktan sonra Tukey çoklu karşılaştırma testi (Tukey, 1949) yapılmıştır.

Elde edilen verilerin istatistiksel analizleri için IBM SPSS ${ }^{\circledR}$ Statistics (Version 20.0, August 2011, SPSS Inc., Chicago, IL, USA) paket programından yararlanılmıştır.

\section{Bulgular ve Tartışma}

Acanthoscelides obtectus erginleri üzerinde farklı uçucu yağların uzaklaştırıcı etki indeks değerleri Tablo 2'de verilmiştir. A. obtectus erginlerinde kekik uçucu yağı cezbedici özellik göstermişken, çay ağacı ve sarımsak uçucu yağları uzaklaştırıcı etki göstermiştir. Bu farklılıklar istatistiksel olarak önemsiz olarak bulunmuştur. A. obtectus erginleri, ardıç ve lavanta uçucu yağ uygulamaları sonucunda kontrol grubuna göre daha fazla yönelim göstermiştir (Şekil 1 ve Tablo 2). Okaliptüs uçucu yağının uygulanmasında ise kontrol grubuna göre daha az yönelim gerçekleșmiştir. Ancak yapılan ikili t testi sonuçlarından oluşan bu farklılıklar istatistiksel olarak önemsiz bulunmuştur (Şekil 1). Kekik uçucu yağının, zararlının erginleri üzerinden hesaplanan uzaklaştırıcı indeksi -25.00 olarak kaydedilmiştir. Çay ağacı ve sarımsak uçucu yağlarının uzaklaştırıcı indeks değerleri de sırasıyla 20.00 ve 18.18 olarak hesaplanmıştır (Tablo 2).

Tablo 2. Farklı uçucu yağların, Acanthoscelides obtectus erginleri üzerinden hesaplanan uzaklaştırıcı indeksleri

\begin{tabular}{lc}
\hline Uçucu yağ & Uzaklaştırıcı indeksi (RI) \\
\hline Ardıç & -9.68 \\
Çay ağacı & 20.00 \\
Lavanta & -11.76 \\
Kekik & -25.00 \\
Okaliptus & 17.39 \\
Sarımsak & 18.18 \\
\hline
\end{tabular}

Oliveira ve ark. (2018) yaptıkları bir çalışmada; Azadirachta indica A. Juss, 1830 (Meliaceae), Cinnamomum zeylanicum J. Presl (Lauraceae), Citrus sinensis (L.) Osbeck (Rutaceae), Eucalyptus sp. L'Hér (Myrtaceae) ve Piper nigrum L. (Piperaceae) bitkilerinden elde edilen uçucu 


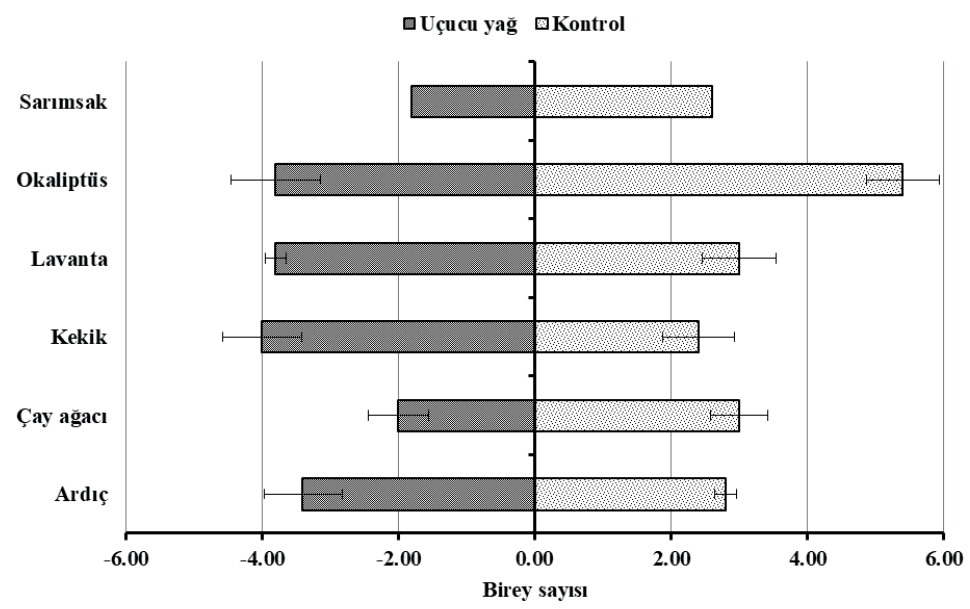

Şekil 1. Farklı uçucu yağların Acanthoscelides obtectus'un erginleri üzerinde uzaklaştırıcı etkileri Paired-samples $\mathrm{t}$ test $\mathrm{p} \leq 0.05, \mathrm{SD}=4, \mathrm{t}_{\text {sarmmsak }}=-0.444, \mathrm{t}_{\text {okaliptus }}=-0.535, \mathrm{t}_{\text {lavanta }}=0.749, \mathrm{t}_{\text {kekik }}=1.725, \mathrm{t}_{\text {cay ağace }}=-0.632, \mathrm{t}_{\text {ardch }}=0.399$

yağlarının $A$. obtectus bireylerinde uzaklaştırıcı etkiye sahip olduğunu bildirmektedir. Bir başka çalışmada ise Citrus reticulata Balonco (Rutaceae) ve C. limonum (L.) Burm.f. (Rutaceae), Mentha piperita L. (Lamiaceae) ve Lavandula angustifolia Mill. (Lamiaceae) uçucu yağlarının A. obtectus bireylerine uygulanması sonucunda en yüksek uzaklaştırıcı etkiye sahip uçucu yağ \% 71.25 ile $M$. piperita olarak kaydedilmiştir (Khelfane-Goucem ve ark., 2016).

A. obtectus erginlerine farklı uçucu yağlarının 1000 ppm $\mathrm{L}^{-1}$ 'lik dozlarının uygulanması sonucunda farklı fumigant etkiler meydana gelmiştir. Uygulamanın 1., 3., 5. ve 7. gün sayım sonuçlarında uçucu yağlar arasında meydana gelen ölüm oranlarında istatistiksel farklılık kaydedilmemiştir. Uygulamanın 1. gün sayım sonuçlarında \% 10.67 ölüm oranı ile çay ağacı uçucu yağı, 7. gün sayım sonuçlarında \% 52.00 ölüm oranı ile lavanta uçucu yağı en yüksek etkiye sahip uçucu yağlar olarak belirlenmiştir (Tablo 3).

Farklı uçucu yağlarının 3000 ppm L L ${ }^{-1}$ lik dozlarının $A$. obtectus erginlerine uygulanması sonucunda farklı fumigant etkiler meydana gelmiştir. Uygulamanın 1., 3., 5. ve 7. gün sayım sonuçlarında uçucu yağlar arasında meydana gelen ölüm oranlarında istatistiksel farklılık kaydedilmemiştir. Denemenin 1. gün sayım sonuçlarında \% 14.67 ölüm oranı ile çay ağacı uçucu yağı en yüksek etkiye sahip bulunmuştur. Denemenin 3. ve 5. gün sayım sonuçlarında $\% 29.22$ ve \% 48.00 ölüm oranları okaliptus uçucu yağı, 7. gün sayım sonuçlarında \% 58.67 ölüm oranı ile ise ardıç uçucu yağı en yüksek etkiye sahip uçucu yağ olarak kaydedilmiştir (Tablo 4).

Farklı uçucu yağlarının 5000 ppm L L'1'lik dozlarının $A$. obtectus erginlerine uygulanması sonucunda farklı fumigant etkiler meydana gelmiştir. Uygulamanın 1., 3., 5. ve 7. gün sayım sonuçlarında uçucu yağlar arasında meydana gelen ölüm oranlarında istatistiksel farklılık kaydedilmemiştir. Denemenin 1., 3., 5. ve 7. gün sayım sonuçlarında ardıç uçucu yağı sırasıyla $\%$ 25.33, \% 30.67, \% 44.00 ve \% 62.67 ölüm oranları ile en yüksek etkiye sahip uçucu yağ olarak kaydedilmiştir (Tablo 5).

Çetin ve ark. (2014) yaptıkları çalışmada $A$. obtectus erginlerine Rosmarinus officinalis L. (Lamiaceae) ve Salvia fruticosa Mill. (Lamiaceae) uçucu yağlarının uygulanması sonucunda $\%$ 100.00; Laurus nobilis L. (Lauraceae), Artemisia dracunculus Ledeb. (Asteraceae) ve Mentha aquatica L. (Lamiaceae) uçucu yağlarının uygulanması sonucunda ise \% 90.00 ölüm oranı meydana geldiğini belirtmişlerdir. Aynı zararlı üzerine Gomortega keule (Molina) Baillon (Gomortegaceae) ve Leurelia sempervirens (Ruiz \&Pav.) Tul. (Atherospermataceae) uçucu yağlarının uygulanması sonucunda \% 100.00 ölüm oranı kaydedilmiştir (Bittner ve ark., 2008).

A. obtectus erginlerine karşı Foeniculum vulgare Mill. (Apiaceae), Origanum vulgare L. (Lamiaceae) ve Syzygium aromaticum L. (Myrtaceae) uçucu yağlarının toksik etkili olduğu bildirilmektedir (Atanasova ve Ganchev, 2018). Yapılan diğer bir çalışmada ise A. obtectus'un dişi bireylerine karş1 Rosmarinus officinalis L. (Lamiaceae) ve Lavandula hybrida L. (Lamiaceae) uçucu yağlarının, erkekler bireylerine karşı ise Mentha microphylla L. (Lamiaceae) ve M. viridis L. (Lamiaceae) uçucu yağlarının toksik etki gösterdiği kaydedilmiştir (Papachristos ve Stamopoulos, 2002).

Acanthoscelides obtectus bireyleri için farklı uçucu yağların uygulanması sonucunda elde edilen LC50 değerleri ise Foeniculum vulgare Mill. (Apiaceae) için $22.30 \mu \mathrm{L} \mathrm{L}^{-1}$, Thymbra spicata L. (Lamiaceae) için $32.40 \mu \mathrm{LL}^{-1}$, Lavandula stoechas 
Tablo 3. Acanthoscelides obtectus erginlerinde farklı uçucu yağların $1000 \mathrm{ppm} \mathrm{L}^{-1}$ ' lik dozlarının uygulaması sonucunda yüzde ölüm oranları

\begin{tabular}{lcccc}
\hline \multirow{2}{*}{ Uçucu yağlar } & \multicolumn{4}{c}{ Uygulama süresi \% ölüm (ortalama \pm standart hata) } \\
\cline { 2 - 5 } & 1. gün & 3. gün & 5. gün & 7. gün \\
\hline Ardıç & $2.67 \pm 2.67$ & $22.67 \pm 6.18$ & $21.67 \pm 6.18$ & $45.44 \pm 9.66$ \\
Çay ağacı & $10.67 \pm 5.42$ & $22.67 \pm 8.59$ & $42.67 \pm 6.53$ & $48.00 \pm 8.26$ \\
Kekik & $5.33 \pm 3.89$ & $20.00 \pm 8.69$ & $32.00 \pm 8.27$ & $44.00 \pm 3.65$ \\
Lavanta & $0.00 \pm 0.00$ & $14.67 \pm 3.27$ & $14.67 \pm 3.27$ & $52.00 \pm 6.21$ \\
Okaliptus & $0.00 \pm 0.00$ & $10.67 \pm 3.40$ & $10.67 \pm 3.40$ & $50.67 \pm 7.35$ \\
Sarımsak & $0.00 \pm 0.00$ & $12.00 \pm 2.49$ & $12.00 \pm 2.49$ & $48.00 \pm 4.47$ \\
\hline
\end{tabular}

Tablo 4. Acanthoscelides obtectus erginlerinde farklı uçucu yağların $3000 \mathrm{ppm} \mathrm{L}^{-1}$ 'lik dozlarının uygulaması sonucunda yüzde ölüm oranları

\begin{tabular}{lcccc}
\hline \multirow{2}{*}{ Uçucu yağlar } & \multicolumn{4}{c}{ Uygulama süresi \% ölüm (ortalama \pm standart hata) } \\
\cline { 2 - 5 } & 1. gün & 3. gün & 5. gün & 7. gün \\
\hline Ardıç & $9.33 \pm 4.99$ & $18.67 \pm 4.42$ & $40.00 \pm 5.16$ & $58.67 \pm 7.42$ \\
Çay ağacı & $14.67 \pm 7.72$ & $25.33 \pm 7.72$ & $30.67 \pm 7.48$ & $50.67 \pm 6.86$ \\
Kekik & $0.00 \pm 0.00$ & $6.67 \pm 5.16$ & $26.67 \pm 11.35$ & $45.33 \pm 13.23$ \\
Lavanta & $0.00 \pm 0.00$ & $28.00 \pm 10.41$ & $34.67 \pm 10.20$ & $53.33 \pm 8.43$ \\
Okaliptus & $1.33 \pm 1.33$ & $29.33 \pm 16.00$ & $48.00 \pm 13.56$ & $52.00 \pm 12.72$ \\
Sarımsak & $8.00 \pm 1.33$ & $12.00 \pm 3.27 \mathrm{a}$ & $24.00 \pm 4.99$ & $50.67 \pm 3.40$ \\
\hline
\end{tabular}

Tablo 5. Acanthoscelides obtectus erginlerinde farklı uçucu yağların 5000 ppm L $\mathrm{L}^{-1}$ 'lik dozlarının uygulaması sonucunda yüzde ölüm oranları

\begin{tabular}{lcccc}
\hline \multirow{2}{*}{ Uçucu yağlar } & \multicolumn{4}{c}{ Uygulama süresi \% ölüm (ortalama \pm standart hata) } \\
\cline { 2 - 5 } & 1. gün & 3. gün & 5. gün & 7. gün \\
\hline Ardıç & $25.33 \pm 12.18$ & $30.67 \pm 11.27$ & $44.00 \pm 7.77$ & $62.67 \pm 7.48$ \\
Çay ağacı & $12.00 \pm 3.27$ & $20.00 \pm 4.71$ & $32.00 \pm 4.90$ & $54.67 \pm 6.46$ \\
Kekik & $2.67 \pm 1.63$ & $6.67 \pm 3.65$ & $22.67 \pm 6.86$ & $61.33 \pm 8.00$ \\
Lavanta & $4.00 \pm 2.67$ & $9.33 \pm 4.00$ & $34.67 \pm 10.83$ & $60.00 \pm 12.47$ \\
Okaliptus & $17.33 \pm 3.40$ & $25.33 \pm 1.33$ & $38.67 \pm 3.89$ & $56.00 \pm 4.52$ \\
Sarımsak & $16.00 \pm 6.86$ & $24.00 \pm 6.86$ & $36.00 \pm 5.81$ & $52.00 \pm 3.27$ \\
\hline
\end{tabular}

L. (Lamiaceae) için $46.30 \mu \mathrm{L} \mathrm{L}^{-1}$ (Selimoğlu ve ark., 2015); Clausena anisata (Willd.) Hook.f.ex Benth (Rutaceae) için $0.093 \mu \mathrm{cm}^{-3}$ (Ndomo ve ark., 2008); Syzygium aromaticum L. (Myrtaceae) için 9.45 $\mu 1 \mathrm{~L}^{-1}$ (Jairoce ve ark., 2016); Myrtus communis L. (Myrtaceae) için $45.31 \mu \mathrm{L}^{-1}$ hava, Laurus nobilis L. (Lauraceae) için $2.36 \mu \mathrm{L}^{-1}$ hava (Karabörklü ve ark., 2010); Lavandula hybrida L. (Lamiaceae), Rosmarinus officinalis L. (Lamiaceae) ve Eucalyptus globulus Labill (Myrtaceae) için 0.80-47.10 $\mathrm{mg} \mathrm{L}^{-1}$ değerleri kaydedilmiştir (Papachristos ve ark., 2004).

\section{Sonuçlar}

Sonuç olarak, depo zararlılarına karşı yoğun olarak kullanılan sentetik insektisitler ve fumigantlardan dolayı insan sağlığı ve çevrenin büyük oranda zarar görmesinden dolayı, yapılan çalışmada her ne kadar uçucu yağlar arasında istatistiksel bir fark olmamasına rağmen bu uygulanan uçucu yağların kullanılması durumunda herhangi bir zararlı etkinin bulunmaması açısından tercih edilebileceklerdir.

\section{Kaynaklar}

Abbott, W.S., 1925. A method of computing the effectiveness of an insecticide. Journal of Economic Entomology, 18(2): 265-267.

Atanasova, D., Ganchev, D., 2018. Fumigant Action of Some Essential Oils Towards Bean Weevil Acanthoscelides obtectus Say. Agricultural University, Plovdiv, Scientific Works, Vol., LXI, Book 2., pp. 145-152.

Bakkali, F., Averbeck, S., Averbeck, D., Idoamar, M., 2008. Biological effects of essential oil-A review. Food and Chemical Toxicology, 46(2): 446-475.

Birgücü, A.K., Çelikpençe, Y., Karaca, İ., 2014. Böcek yumurtası ve konukçu bitki arasındaki karşıllklı ilişkiler. Türkiye Entomoloji Bülteni, 4(2): 107-119.

Birgücü, A.K., Çelikpençe, Y., Akdaş, A., Gökkaya, S., Karaca, I.,, 2016. Farklı uçucu yağların Trialeurodes vaporariorum'un yumurta bırakma davranışı üzerine etkileri. Türkiye Entomoloji Bülteni, 6(3): 213-220.

Bittner, M., Casanueva, M.E., Arbert, C.C., Aguilera, M.A., Hernández, V.J., Becerra, J.V., 2008. Effects of essential oils from five plant species against the granary weevils Sitophilus zeamais and 
Acanthoscelides obtectus (Coleoptera). Journal of the Chilean Chemical Society, 53(1): 1455-1459.

Chu, S.S., Ru Liu, Q., Long Liu, Z., 2010. Insecticidal activity and chemical composition of the essential oil of Artemisia vestita from China against Sitophilus zeamais. Biochemical Systematics and Ecology, 38(4): 489-492.

Coast, J.R., 1994. Risks from natural versus synthetic insecticides. Annual Review of Entomology, 39(1): 489-515.

Çetin, H., Uysal, M., Şahbaz, A., Alaoğlu, Ö., Akgül, A., Özcan, M.M., 2014. Tıbbi ve aromatik bitki uçucu yağlarının fasulye tohum böceği [Acanthoscelides obtectus Say (Coleoptera: Chrysomelidae)] erginlerine fumigant etkileri. Selçuk Tarım Bilimleri Dergisi, 1(1): 6-11.

Dobie, P., Haines, C.P., Hodges, R.J., Prevett, P.F., 1984. Insects and Arachnids of Tropical Stored Products, Their Biology and Identification: A Training Manual. Tropical Development and Research Institute, UK.

Ebadollahi, A., 2011. Iranian plant essential oils as sources of natural insecticide agents. International Journal of Biological Chemistry, 5(5): 266-290.

Gallo, D., Nakano, O., Silveria Neto, S., Carvalho, R.P.L., Batista, G.C., Berti Filho., E., Parra, J.R.P., Zucchi, R.A., Alves, S.B., Vendramim, J.D., Marchini, L.C., Lopes, JR.S., Omoto, C., 2002. Entomologia Agrícola Piracicaba: FEALQ, 920p.

Huang, F., Subramanyam, B., 2005. Management of five stored-product insects in wheat with pirimiphosmethyl and pirimiphos-methyl plus synergized pyrethrins. Pest Management Science, 61(4): 356-362.

Isman, M.B., 2006. Botanical insecticides, deterrents, and repellents in modern agriculture and an increasingly regulated world. Annual Review of Entomology, 51(1): 45-66.

Jairoce, C.F., Teixeira, C.M., Nunes, C.F.P., Nunes, A.M., M.P. Pereira, C.M.P., Garcia, F.R.M., 2016. Insecticide activity of clove essential oil on bean weevil and maize weevil. Revista Brasileira de Engenharia Agrícolae Ambiental, 20(1): 72-77.

Jembere, B., Obeng-Ofori, D., Hassanali, A., Nyamasyo, G.N.N., 1995. Products derived from the leaves of Ocimum kilimanndscharicum (Labiatae) as postharvest grain protectants against the infestation of three major stored product insect pests. Bulletin of Entomological Research, 85(3): 361-367.

Jimenez, J.C., Fuente, M., Ordas, B., Dominguez, L.E.G., Malvar, R.A., 2017. Resistance categories to Acanthoscelides obtectus (Coleoptera: Bruchidae) in terapy bean (Phaseolus acutifolius), new sources of resistance for dry bean (Phaseolus vulgaris) breeding. Crop Protection, 98(C): 255-266.

Karabörklü, S., Ayvaz, A., Yılmaz, S., 2010. Bioactivities of different essential oils against the adults of two stored product insects. Pakistan Zoological Society, 42(6): 679-686.

Khelfane-Goucem, K., Lardjane, N., Medjdoub-Bensaad, F., 2016. Fumigant and repellent activity of Rutaceae and Lamiaceae essential oils against Acanthoscelides obtectus Say. African Journal of Agricultural Research, 11(17): 1499-1503.

Lee, S.E., Lees, E.M., 2001. Biochemical mechanisms of resistance in strains of Oryzaephilus surinamensis (Coleoptera: Silvanidae) resistant to malathion and chlorpyrifos-methyl. Journal of Economic Entomology, 94(3): 706-713.

Mueller, D.K., 1990. Fumigation. In: A. Mallis (Ed.), Handbook of pest control, Franzak and Foster Co., Cleveland, Ohio, USA, pp. 901-939.

Nerio, L.S.N., Olivero-Verbel, J., Stashenko, E., 2009. Repellent activity of essential oils from seven aromatic plants grown in Colombia against Sitophilus zeamais Motschulsky (Coleoptera). Journal of Stored Products Research, 45(3): 212-214.

Ndomo, A.F., Ngamo, L.T., Tapondjou, L.A., Tchouanguep, F.M., Hance, T., 2008. Insecticidal effects of the powdery formulation based on clay and essential oil from the leaves of Clausena anisata (Willd.) J.D. Hook ex. Benth. (Rutaceae) against Acanthoscelides obtectus (Say) (Coleoptera: Bruchidae). Journal of Pest Science, 81(4): 227-234.

Oliveira, M.R., Silva Bonome, L.T., Hertwig Bittencourt, H., Zarowni, E., Silva Lefchak, L., 2018. Alternative treatments in bean seeds for repelling Acanthoscelides obtectus (Say). Journal of Seed Science, 40(4): 362-369.

Okonkwo, E.U., Okoye, W.I., 1996. The efficacy of four seed powders and the essential oils as protectants of cow-pea and maize grain against infestation by Callosobruchus maculatus (Fabricius) (Coleoptera: Bruchidae) and Sitophilus zeamais (Motschulsky) (Coleoptera: Curculionidae) in Nigeria. International Journal Pest Management, 42(3): 143-146.

Papachristos, D.P., Karamanoli, K.I., Stamopoulos, D.C., Menkissoglu-Spiroudi, U., 2004. The relationship between the chemical composition of three essential oils and their insecticidal activity against Acanthoscelides obtectus (Say). Pest Management Science, 60 (5): 514-520.

Papachristos, D.P., Stamopoulos, D.C., 2002. Toxicity of vapours of three essential oils to the immature stages of Acanthoscelides obtectus (Say) (Coleoptera: Bruchidae). Journal of Stored Products Research, 38(4): 365-373.

Pascual-Villalobos, M.J., Robledo, A., 1998. Screening for anti-insect activity in Mediterranean plants. Industrial Crops and Products, 8(3): 183-194.

Regnault-Roger, C., Vincent, C., Arnason, J.T., 2012. Essential oils in insect control: low-risk products in a high-stakes world. Annual Review of Entomology, 57(1): 405-424.

Pemonge, J., Pascual-Villalobos, M.J., Regnault-Roger, C., 1997. Effects of material and Extracts of Trigonella foenum-graecum L. Against the Stored Product Pests Tribolium castaneum (Herbst) (Coleoptera: Tenebrionidae) and Acanthoscelides obtectus (Say) (Coleoptera: Bruchidae). Journal Stored Products Research, 33(3): 209-217.

Roel, A. R., Vendramim, J.D., 2006. Residual effect of ethyl acetate extract of Trichilia pallida Swartz 
(Meliaceae) for Spodoptera frugiperda (J.E. Smith, 1797) (Lepidoptera: Noctuidae) larvae of diferents ages. Ciencia Rural, 36(4): 1049-1054.

Selimoğlu, T., Gökçe, A., Yanar, D., 2015. Bazı bitki uçucu yağlarının Acanthoscelides obtectus (Say) (Coleoptera: Bruchidae) üzerindeki fumigant toksisiteleri. Türkiye Entomoloji Dergisi, 39(1): 109118
Tripathi, K.A., Upadhyay, S., Bhuiyan, M., Bhattacharya, P.R., 2009. A review on prospects of essential oils as biopesticide in insect-pest management. Journal of Pharmacognosy and Phytotherapy, 1(5): 52-63.

Tukey, J.W., 1949. Comparing Individual Means in the Analysis of Variance. Biometrics, 5(2): 99-114.

Yıldırım, E., Özbek, H., Aslan, G., 2001. Depolanmış Ürün Zararlıları. Atatürk Üniversitesi, Ziraat Fakültesi Yayınları, 191, Erzurum. 